
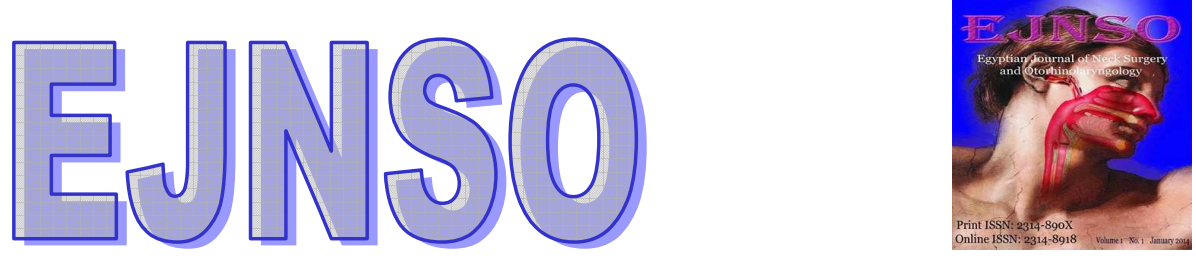

\title{
Intratympanic Corticosteroids Injection for Idiopathic SuddenSensorineural Hearing Loss: A Meta-analysis
}

\author{
Essam A Abo El- Magd ${ }^{\mathrm{a}}$, Ahmed G. Abd Rahem ${ }^{\mathrm{a}}$, Samar S. Ahmed \\ ${ }^{a}$ Lecturer of Otorhinolaryngology, E.N.T. Department, Qena Faculty of Medicine, South Valley University, Egypt. \\ ${ }^{\mathrm{b}}$ Lecturer of Community Medicine, E.N.T. Department, Qena Faculty of Medicine, South Valley University, Egypt.
}

Received: April $24^{\text {th }}, 2014$.

Revised: June $26^{\text {th }}, 2014$

Accepted: December $1^{\text {st }}, 2014$

Keywords:

intratympanic steroids; idiopathic sudden

sensorineural hearing loss

\begin{abstract}
Objectives: Idiopathic sudden sensorineural hearing loss (ISSNHL) is an urgent health problem that required rapid interference to help in improvement of hearing loss and prevent further deterioration. Systemic steroids were used in treatment of ISSNHL with all what is known of its adverse effects. Therefore, this study aimed to evaluate the effectiveness of intratympanic steroid application in patients suffering from ISSNHL if used as follows: as primary therapy, salvage therapy after failure of systemic steroid or as adjuvant therapy with systemic steroid.

Study design: Meta-analysis review of literature.

Methods: Searching at the pub-med (Medline database) for articles including the following key words: intratympanic steroids in ISSNHL or efficacy of intratympanic steroids in ISSNHL. The included articles were 8 articles that fulfilled the inclusion criteria.

Data collection: The data collected from the chosen 8 articles.

Data analysis: Data analysis was performed utilizing meta-analytic review manger (RevMan5) software.

Conclusions: Intratympanic steroid therapy is effective in treatment of ISSNHL alone or as a salvage therapy after failure of systemic steroids or in combination with systemic steroid.
\end{abstract}

\section{Introduction}

Idiopathic sudden sensorineural hearing loss (ISSNHL) is considered an otologic emergency requiring immediate and careful clinical intervention, followed by appropriate and specific treatment (Ahn et al., 2007). ISSNHL is defined as the rapid decline in hearing in less than 3 days $>20$ $\mathrm{dB}$ in $>3$ contiguous audiometric frequencies without any identifiable cause (Byle, 1984). ISSNHL occurs over a short period of time and its degree may vary from a mild to profound hearing impairment in otherwise normal hearing individuals. The disorder has an estimated incidence of 5-20 cases per100.000 populations (Mattox et al., the hearing drops over a few minutes or few hours, or patients awaken in the morning with hearing loss. This condition however constitutes a medical emergency because the window of opportunity for treatment is narrow and early administration of steroids is more efficacious than watchful waiting (Rauch, 2004). No single treatment exists leading to complete recovery to pre- hearing loss levels. Proposed treatments have included vasodilators, steroids (Intratympanic or systemic), antiviral agents, hyperbaric oxygen and plasmapheresis (Slattery et al., 2005). The use of steroids is due to the work of Wilson, (1983) who demonstrated recovery rate of $60 \%$ after systemic steroid therapy. IT 


\section{Essam A Abo El- Magd, Ahmed G. Abd Rahem, Samar S. Ahmed \\ / (EJNSO) Vol. 2, No. 1; Jan (2015) 19- 24}

steroids delivery in the middle ear was introduced 50 years ago by Schuknecht, (1986) for the treatment of Meniere's disease as cited by Jackson and Silverstien, 2002. The first report of IT steroids in treatment of ISSNHL was by Silverstien, (1996) followed by Parnes, (1999).

The primary reason for the use of IT steroid without systemic steroids is in patients who can't tolerate systemic steroids or those who at greater risk for complications from systemic steroids e.g. Diabetes mellitus (Lefebre and Staeker, 2002).

The uses of Intratympanic steroids have evolved into 3 main protocols for treatment of ISSNHL:

As an initial or primary treatment for ISSNHL without systemic steroids.

As adjunctive treatment given concomitantly with systemic steroids for ISSNHL.

$\square$ As salvage therapy after failure of systemic steroids for ISSNHL (Haynes et al., 2007).

Meta-analysis is a quantitative statistical procedure that synthesizes findings across many studies, overcoming the problems of small samples and diverse outcomes and programs. According to Tobler (1986), the computation of the effect size is dependent on statistically significant results. Instead of discounting the studies whose results do not reach statistical significance, as would be the case in a literature review, the quantitative results of each study are converted into a common metric (effect size) allowing comparison of results across studies.

\section{Methods:}

Searching at the pub-med (Medline database) for articles including the following keywords:

-Intratympanic steroids in ISSNHL.

-Efficacy of Intratympanic steroids in ISSNHL. The search was limited to articles published in English language and human studies till 1/5/2013 the search resulted in 248 abstract out of them 52 articles was relevant to the target.

Table (1): Summary of screening of articles.

\begin{tabular}{|l|c|c|}
\hline \multicolumn{1}{|c|}{ Keywords } & $\begin{array}{c}\text { Number of } \\
\text { articles and } \\
\text { their abstracts }\end{array}$ & Relevant \\
\hline $\begin{array}{l}\text { Intratympanic steroids, } \\
\text { ISSNHL, efficacy of IT } \\
\text { steroids in SHL }\end{array}$ & 248 & 52 \\
\hline
\end{tabular}

The screening form of articles was used by the investigators to screen the articles which were yielded by the Medline search after blinding the author name and journal name. Screen form of the articles:

(1) Irrelevant articles: articles that miss one or more of the above keywords.

(2) Relevant articles: articles which contain the above keywords.

(3) Included articles: These are 8 articles which fulfilled the following inclusion criteria:

Randomized control trial studies.

Number of patients were mentioned in study and control group.

hours

Acute onset of hearing loss within 24-72

Unilateral or bilateral hearing loss.

Hearing loss of $20 \mathrm{~dB}$ or more in at least 3 contiguous audiometric frequencies.

No otologic history in the affected ear.

Description of the approach.

Using IT steroids as primary treatment, salvage treatment or in combination with systemic steroids.

Functional outcome is mentioned.

\section{Results:}

The data were collected from the chosen 8 articles fulfilling the previously mentioned criteria. Data analysis was

performed utilizing Meta-analytic Review Manager (RevMan 5) software. The results of the data collected from the chosen articles were fed into the above mentioned (RevMan 5) software. 


\section{Essam A Abo El- Magd, Ahmed G. Abd Rahem, Samar S. Ahmed \\ / (EJNSO) Vol. 2, No. 1; Jan (2015) 19- 24}

Table 2: Meta-analysis for Intratympanic steroids use in ISSNHL.

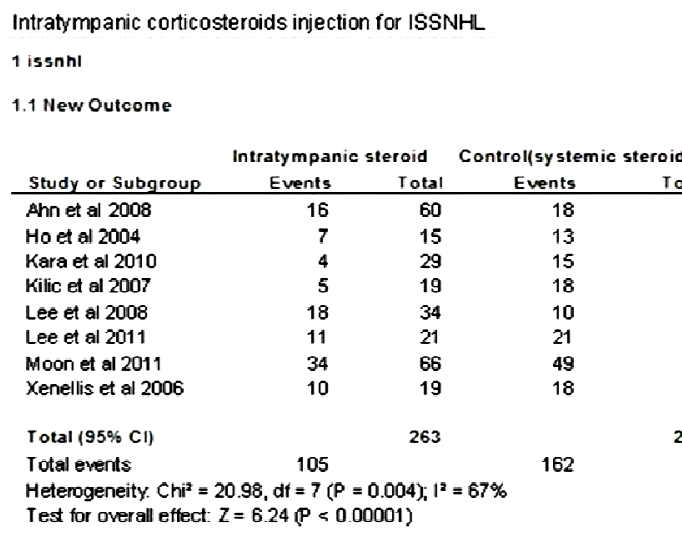

16 Total

$\begin{array}{rr}\text { Total } & \text { Events } \\ 10 & 18\end{array}$

$\begin{array}{ll}18 & T \\ 13 & \end{array}$

Total ( $95 \% \mathrm{Cl})$

Total events

Hetemgeneity $C \mathrm{Chi}^{2}=20.98, \mathrm{dt}=7(\mathrm{P}=0.004): \mathrm{I}^{2}=67 \%$

Test for overall effect: $Z=6.24(P<0.00001)$

There was a significant difference between systemic steroids and Intra-tympanic steroids administration.

Table 3: A comparison between many articles done on intratympanic steroid perfusion in ISSNHL (Haynes et al, 2007).

\begin{tabular}{|c|c|c|c|}
\hline Author & Percent Improved & Criteria for Improvement & Current Study With Applied Criteria \\
\hline Silverstein et al., 121996 & $25 \%$ & $\begin{array}{l}10-d B \text { PTA } \\
15 \% \text { SDS }\end{array}$ & $32.5 \%$ \\
\hline Parnes, 13 1999\$ & $46 \%$ & $\begin{array}{l}5 \text { normal thresholds } \\
\text { One serviceable hearing }\end{array}$ & $\begin{array}{l}40 \% \\
\text { (57\% if including only patients } \\
\text { treated within } 6 \text { wks) }\end{array}$ \\
\hline Kopke et al., 172001 (>6 wks) † & $0 \%$ & $\begin{array}{l}10-d B \text { PTA } \\
15 \% \text { SDS }\end{array}$ & $0 \%$ \\
\hline Kopke et al.,17 2001 ( $<6$ wks) & $83 \%$ & $\begin{array}{l}10-d B \text { PTA } \\
15 \% \text { SDS }\end{array}$ & $\begin{array}{l}35 \% \text { overall } \\
\text { (50\% if including only patients } \\
\text { treated within } 6 \text { wks) }\end{array}$ \\
\hline Chandrasekhar, 142001 & $73 \%$ & $\begin{array}{l}\text { Increase in SDS, decrease in } \\
\text { PTA }\end{array}$ & $40 \%$ \\
\hline Gianoli and Li, ${ }^{15} 2001$ & $44 \%$ & $\begin{array}{l}10-d B \text { PTA } \\
10 \% \text { SDS }\end{array}$ & $40 \%$ \\
\hline Lefebre and Staeker, 162002 & $100 \%$ & $>16 \mathrm{~dB}$ improvement in PTA & $\begin{array}{l}12.5 \% \text { (overall) } \\
50 \% \text { if treated within } 10 \text { days }\end{array}$ \\
\hline Gouveris, 192003 & Complete recovery (CR): & $\begin{array}{l}\text { CR: within } 10 \mathrm{~dB} \text { of unaffected } \\
\text { ear }\end{array}$ & CR $2.5 \%$ \\
\hline & Partial: $39 \%$ & $\begin{array}{l}\text { NR: less than 10-dB } \\
\text { improvement }\end{array}$ & Partial $15 \%$ \\
\hline Jackson, ${ }^{18} 2002$ & $\begin{array}{c}\text { No recovery: (NR) } 28.6 \% \\
31 \%\end{array}$ & Positive response & $\begin{array}{l}\text { NR } 82.5 \% \\
40 \%\end{array}$ \\
\hline Ho et al., 202004 & $53 \%$ & 30-dB PTA & $\begin{array}{l}7.5 \% \\
(10.3 \% \text { if only those treated within } \\
50 \text { days) }\end{array}$ \\
\hline Herr and Marzo,21 2005 & $53 \%$ & $\begin{array}{l}10 \mathrm{~dB} \text { PTA } \\
20 \% \text { SDS }\end{array}$ & $\begin{array}{l}32.5 \% \\
(33.3 \% \text { if only those treated within } \\
20 \text { wks) }\end{array}$ \\
\hline Battista,24 2005‡ & $\begin{array}{l}8 \% \text { full } \\
12 \% \text { partial }\end{array}$ & $\begin{array}{l}\text { Full within } 10 \mathrm{~dB} \text { baseline } \\
\text { Partial within } 50 \mathrm{~dB} \text { baseline }\end{array}$ & $\begin{array}{l}2.5 \% \text { full } \\
10 \% \text { partial overall }\end{array}$ \\
\hline Slattery et al., 2005 & $55 \%$ & 10-dB PTA & $\begin{array}{l}40 \%(42.1 \% \text { if only those treated } \\
\text { within } 3 \text { months) }\end{array}$ \\
\hline Choung et al., 252006 & $38.2 \%$ & $\begin{array}{l}12 \% \text { SDS } \\
10 \% \text { P PTA } \\
15 \% \text { SDS }\end{array}$ & $\begin{array}{l}35 \% \\
\text { (10\% if treated after } 28 \text { days) }\end{array}$ \\
\hline $\begin{array}{l}\text { Dallan et al., } 26,2006 \\
\text { Xenellis } 272006\end{array}$ & $\begin{array}{l}75 \% \\
47 \%\end{array}$ & $\begin{array}{l}15 \mathrm{~dB} \text { PTA } \\
10 \mathrm{~dB} \text { PTA }\end{array}$ & $\begin{array}{l}12.5 \%(5 \% \text { if treated after } 21 \text { days) } \\
15 \%(5 \% \text { if treated after } 2 \text { days) }\end{array}$ \\
\hline
\end{tabular}




\section{Essam A Abo El- Magd, Ahmed G. Abd Rahem, Samar S. Ahmed \\ / (EJNSO) Vol. 2, No. 1; Jan (2015) 19- 24}

\section{Discussion:}

Sudden sensorineural hearing loss is an otologic emergency; which represents a symptom or clinical sign rather than a disease. It occurs in 5-20 per 100.000 populations. Although various methods of management have been used in the literature, systemic steroids were the most widely used medication.

In this study we aimed to compare the effect of IT steroids in the treatment of ISSNHL; while treating another group of patients with systemic steroids as a control .The search was done through the Pubmed, where 52 articles relevant to the target were found, in which 44 articles were excluded because they didn't fulfill the inclusion criteria and only 8 articles fulfilled the inclusion criteria. Data analysis was performed utilizing Metaanalytic Review Manger. Meta-analysis is a systematic approach to identify, appraise, synthesize and combine the results of relevant studies to reach to conclusions. All the studies analyzed during this metaanalysis were randomized controlled trials. The results of this Meta-analytic study as regard response of hearing to IT steroids showed that there is a significant improvement in hearing results in patients receiving local steroids against to the control group that received systemic steroids alone.

The total number of patients included in the meta-analysis were 506 suffers from ISSNHL, 263 received Intratympanic steroid therapy and 243 received systemic steroids, among them 158 patients improved after receiving Intratympanic steroids, and only 81 patients improved after receiving systemic steroids. The included studies were HO, 2004; Kara, 2010; Kilic, 2007; Lee, 2011; Moon, 2011; and Xenellis, 2006 and their colleagues. All these studies showed significant improvement of hearing with intratympanic steroids therapy versus systemic steroids. On the contrary Ahn et al., 2007 and Lee et al., 2008 state that there is no significant improvement of hearing after addition of intratympanic steroids to systemic steroids. The results of this Meta-analytic study support the former theory; that is, intratympanic steroid therapy is significantly effective in treatment of ISSNHL. These findings also agree with Xenellis et al., 2006; Moon et al., 2011; Lee et al., 2011; Kilic et al., 2007; Kara et al., 2010 and Ho et al., 2004.

IT steroids administration as an alternative modality for ISSNHL appears attractive because it avoids the systemic side effects of steroids and also obtains a higher inner ear concentration than systemic steroids. Steroids seem to be efficacious regardless of the etiology involved because of their antiinflammatory effect which is based on the inhibition of pro-inflammatory cytokine secretion, immunosuppressive activity, neuroprotective, antioxidant and antiapoptotic effect. These drugs are the only form of treatment that has been shown to be effective in clinical trial, as there are glucocorticoid and mineralocorticoid receptors in the inner ear.

IT steroid therapy is used either as an initial therapy or adjuvant therapy with systemic steroids or as salvage therapy after systemic steroids failure. Parnes et al., 1999 and Chandrasekhar, 2001 reported relatively successful results with IT steroids therapy as an initial therapy in ISSNHL instead of systemic steroids, but in our study no one of included studies used IT steroids as initial therapy. It was found that IT steroids have better concentration in the inner ear fluids than systemic steroids (Chandrasekhar, 2001). Comparing the perilymph steroid concentration between the intravenous and IT administration of 
the drug, the local usage was significantly more effective than systemic administration.

\section{Conclusion:}

Intratympanic steroid therapy is effective in treatment of ISSNHL either as a salvage therapy after failure of systemic steroids or in combination with systemic steroids.

\section{References:}

1-Ahn Joong HO. Myung Woul Han, Ji Heui, and Jong WOO Chung and Tae Hyun Yoon.: Therapeutic effectiveness over time of IT dexamethasone as salvage treatment of sudden deafness, Acta otolaryngologica 2007; 128: 128-131.

\section{2-Battista Robert A., MD,} FACS: Chicago: Intratympanic dexamethasone for profound idiopathic sudden sensorineural hearing loss, otolaryngol head and neck surg 2005; 132:902-905.

3-Byle FMJ: Sudden hearing loss: Eight years of experience and suggested prognostic table. Laryngoscope 1984; 94:647-651.

4-Chandrasekher Sujana S.:
Intratympanic dexamethasone for
sudden sensorineural hearing loss, clinical
and laboratory evaluation. Otol Neurotol
2001; 22:18-23.

5-Cole RR, Jahrdoesfer RA.: Sudden hearing loss: an update Am J otol 1988; 9:211-215.

6-Dallan Lacopo, Luca Bruschini, Andrea Nacci, Paolo Bruschini, Claudio Traino, Ferdinando

7-Rognini and Bruno Fattori.: Transtympanic steroids as a salvage therapy in SHL preliminary results. ORL 2006; 68:247-252.

8-Gianoli GJ and LI JC.: Transtympanic steroids for treatment of sudden hearing loss. Otolaryngol head and neck surgery, 2001; 125:142-146.
9-Gouveris Haralampos, Oksana Selivanova and Wolf Mann.: Intratympanic dexamethasone with hylouronic acid in the treatment of ISSNHL after failure of intravenous steroids and vasoactive

therapy. Eur Arch Otolaryngol, 2003; 262: 131-134.

10-Haynes DS, O'Malley, Cohen S: IT dexamethasone for sensorineural hearing loss after failure of systemic therapy. Laryngoscope, 2007; 117:3-15.

11-Herr Brian D. and Marzo Samj.: Intratympanic steroid perfusion for refractory sudden sensorineural HL. Otolaryngol head and neck surgery, 2005; 132:527-531.

12-HO Guan-Min, Lin Hung-Ching, Shu Min-Tsan, Yang Cheng- Chien, Tsai Hsun-Tien.: Effectivness of IT dexamethasone injection in sudden deafness as salvage therapy. Laryngoscope, 2004;114:1184-118.

13-Jackson Lance E. and Silverstien Herbert.: Chemical perfusion of inner ear, otol laryngol Chin Nam, 2002; 33:639-653.

14-Kara E, Cetik F, Tarkan O, Surmelioglu $\quad$ O.: $\quad$ Modified intratympanic treatment for idiopathic sudden sensorineural hearing loss, Eur Arch Otorhinolaryngol, 2010;701-7.

15-Kilic Rahmy, Safak Mustafa Asim, Haldun Oguz, Selda Kargin, Munir Demirci,Erdal Samim, and Levent Naci Ozluoglu.: methylprednisolone for sensorineural hearing loss. Oto Neurotol, 2007; 28:312-316.

16-Kopke RD, Hoffer ME, Wester D, O'Leary, and MJ Jackson RL.: Targeted topical steroid therapy in ISSNHL. Otol Neurotol, 2001; 22:475479.

17-Lee HS, Kim JM, Kim YJ, Chung DH, Seo BS, Kim SH.: Results of intratympanic dexamethasone injection as salvage treatment in idiopathic sudden hearing loss. J Otolaryngol Head Neck Surg, 2008;263-8. 


\section{/ (EJNSO) Vol. 2, No. 1; Jan (2015) 19- 24}

18-Lee JB, Choi SJ, Park HY, Choo OS, Choung YH.: The efficacy of intratympanic dexamethasone injection as a sequential treatment after initial systemic steroid therapy for sudden sensorineural hearing loss. Eur Arch Otorhinolaryngol, 2011; 833-9.

19-Lefebre PP and Staekher H.: Steroid perfusion of the inner ear for SSNHL after failure of conventional therapy: a pilot study. otolaryngol head and neck surgery, 2002; 122:698-702.

20-Mattox DE, Simmon FB.: Natural history of ISSNHL. Ann otol Rhinol Laryngol, 1977; 86:463-480.

21-Moon IS, Lee JD, Kim J, Hong SJ, Lee WS.: Intratympanic dexamethasone is an effective method as a salvage in refractory sudden hearing loss. Otol Neurotol, 2011; 1432-6. 22-O'Malley Mathew, Haynes David S., and Seth Cohen.: Intra- tympanic dexamethasone for ISSNHL. Laryngoscope, 2008; 117:3-15.

23-Parnes LS, Sun AH, Freedman DJ.: Corticosteroid Pharmacokinetics in the inner ear fluids: animal study followed by clinical application. Laryngoscope, 1999; 109: 1-17.

24-Rauch Steven D.: IT steroids for sensorineural hearing loss. Otolaryngol Chin Am, 2004; 37:1061-1074.I

25-Schuknecht HF.: Pathology of the ear. $2^{\text {nd }}$ ed. Philadelphia: lea and Febiger, 1993.

26-Silverstien Herbert, P. Todd Rowan, Michael J. Olds, and Seth I.Rosenberg.: Inner ear perfusion and the role of round window patency Am $\mathrm{J}$ otol 1996;18:586-589.

27-Slattery WH, Fisher LM, Iqbal Z, Friedman RA and Liu N.: Intratympanic steroid for the treatment of ISSNHL otolaryngol head and neck surgery, 2005; 133:251-259.

28-Tobler NL: Meta-analysis of 143 adolescents drug prevention Programs. Drug Issues, 1986; 16:537-56.

29-Wilson WR, Veltri RW, Laird N, Sprinkle PM.: Viral and epidemiologic studies of ISSNHL. Otolaryngol head and neck surgery 1983; 91:653-658.
30-Xenellis
John,
Nikolaos Papadimitriou, Thomas Nikolopoulos: IT steroid treatment in ISSNHL a control study. The American academy of otolaryngology-Head and Neck surgery, 2006; 134:940-945. 